\title{
Enhancing Healthcare System in Ghana through Integration of Traditional Medicine
}

\author{
Emmanuel Asante \& Raphael Avornyo (PhD) \\ Department of Sociology and Anthropology, University of Cape Coast, \\ Cape Coast, Ghana.
}

\author{
Accepted: Sep 03, 2013 Published: October 10, 2013 \\ Doi:10.5296/jsr.v4i2.4224 URL: http://dx.doi.org/10.5296/jsr.v4i2.4224
}

\begin{abstract}
Traditional Medicine (TM) has been practised in Ghana from time immemorial and many Ghanaians still patronise the services of traditional medical practitioners (TMPs). However, TM has not been integrated into the formal healthcare delivery system of the country. This might be partly due to attitudes and perceptions towards it. The aim of the study was to find out the attitudes and perceptions of Scientific Medical Practitioners (SMPs) towards TM in Ghana and then propose measures for the full integration of TM into Ghana's healthcare delivery system. A descriptive survey methodology was used to solicit responses from all 33 SMPs practising in the Central Region of Ghana. An in-depth interview and self administered questionnaire were the main instruments used for data collection. The main result of the study is that, although SMPs would want the full integration of TM into the formal healthcare delivery system, when confronted with possible ways of working with TMPs they showed reluctance to accepting them as equal partners since they perceived their practice as inferior to theirs. In order to reduce the mistrust and lack of understanding of the philosophy that underlie Scientific Medicine and Traditional Medicine, there must be regular consultations and dialogue between and among practitioners of the two medical systems. This may engender the needed trust and respect that the practitioners need to accord each other in order to develop and integrate TM into the national healthcare system.
\end{abstract}

Keywords: attitudes, integration, perception, scientific medical practitioners, traditional medicine.

\section{Introduction}

Ghana has operated a plural medical system since the introduction of scientific medicine(SM) into the country in the early $19^{\text {th }}$ century (Twumasi, 1975). The two dominant medical systems which are distinct and have operated side-by-side are scientific medicine and traditional medicine (TM). The former, receives state support and has consequently become the official medical model with developed infrastructures and human resources. It is heavily funded by the state. P.A. Twumasi (1975) argues that scientific medicine has brought obvious 'benefits' to the country. For example, it has helped to lower the death rate and has increased 
the life expectancy of the people. But Sarpong (2008) has observed that though it caters for only 30 per cent of the population, it takes the chunk of the national budget because of its high cost of service.

The indigenous medical paradigm that existed prior to the introduction of scientific medicine into Ghana has persisted up to today. It has been sustained mainly by private entrepreneurs and practitioners who receive little or no assistance from the state. This paper argues that a wealth of theoretical and empirical evidence exists to suggest that integrating the two systems would enhance healthcare delivery in Ghana. The paper argues further that the idea of holism vividly expressed in indigenous medical practice, when incorporated in the mainstream medical system, will provide an effective framework for "relatively coherent and synergistic" practices for healthcare in Ghana (Alester 1989; Lowenberg 1989; Mattson 1982).

\section{Theoretical perspectives on integration}

The process of integration is examined within the framework of negotiated order theory developed by Anselm Strauss et al. (1963), for studying how healthcare systems emerge. It is a useful tool for understanding the process of integrating the existing health systems in Ghana. The theory holds that health systems or organizations occur as individual health practitioners, departments and stakeholders negotiate the terms of interactions with each other. Strauss and colleagues (Negotiations, 1978) see health systems as something health practitioners must work out through negotiation, "succession of conflicts, accommodation, and assimilation". The negotiated order therefore, emerges when practitioners or institutions jointly collaborate in constructing their common goal and how to achieve that goal (Crozier and Friedberg, 1980). In a negotiated order, there is therefore a convergence of interests and actions to promote a common purpose. When actors have a shared goal, they develop a common appreciation of the contributions of each other (Boje, 1982). As a result they create shared meanings, perceptions and understanding of the tasks and operations to achieve that common goal.

\section{The concept of Integration}

Hyma and Ramesh (1994) observed that the term "integration" lacks one precise definition. "Integration" in this paper means a process of incorporating TM into the formal healthcare delivery system. This involves the introduction of traditional medicines, techniques and knowledge into the country's mainstream healthcare delivery system. Furthermore, integration denotes the exposure of the practitioners of both systems to the philosophies and theories of the systems in order to provide an effective preventive and curative treatment for all Ghanaians. Hyman and colleague indentified four types of integration.

\section{Institutional integration}

Hyma and Ramesh (1994:72) describe institutional integration as the "process in which formal health services begin to incorporate and work with TM for the benefit of the whole population". Under institutional integration, TM is given an official recognition through policies and legislation. The WHO's report cited in Hyma and Ramesh (1994) notes that 
institutional integration has usually been triggered at Primary Health Care (PHC) level by the prevalence of conditions such as inadequate resources in terms of personnel, buildings, materials and finance. Institutional integration has proven to be very beneficial to both TMPs and SMPs because through the healthcare providers learn from each other and have a harmonious co-existence. It also promotes increase in the numerical strength of the practitioners, thereby eventually widening the healthcare coverage for the population. Notwithstanding these numerous benefits that can be derived from the implementation of institutional integration as enumerated above, it should be noted that the practice is fraught with some problems. One major weakness is that, with the exception of China, TM and TMPs usually occupy a subordinate position wherever institutional integration policy has been implemented (Hyma and Ramesh, 1994).

\section{Consumer engendered integration}

Consumers' choice of healthcare services in a pluralistic medical system could stimulate integration (Bodeker, 2001). As Bodeker (2001) observed, consumer engendered integration (CEI) usually emerges spontaneously mainly due to clients' movement from one medical system to another or the simultaneous utilization of several systems at the same time. The multiple uses of healthcare services, as Twumasi (1988), Senah (1997) and Bonsi (2000) note, may be due to a perception of the effectiveness of treatment and nature of the illness. Similarly, the 'shopping' for health care services in a pluralistic medical system has been attributed to "cost, expectations of long term cure, previous knowledge, beliefs, familiarity, experience and social contacts" (Hyma and Ramesh,1994:78). For example, in Ghana, individuals who suffer fractures access the services of both TMPs.

\section{Integration through adaptation}

Another form of integration has emerged from the attempt by some TMPs especially those who have received training in some aspects of scientific medical practices to supplement traditional medical practice with ideas and technology from scientific medicine, which Twumasi (1975:120) in his study of Medical Systems in Ghana designated as 'adaptation of traditional medical practice'. According to (Twumasi 1975), adaptation of traditional medical practice (hereafter called adaptation) appears in two main forms: non-structural and structural. In the non-structural sphere the TMPs adopt modern paraphernalia of scientific medicine such as telephones, business cards, reception rooms, consulting rooms and the use of white over-all coats. Others also make use of modern computers and diagnostic kits such as thermometers, stethoscopes and X-Rays. Twumasi (1975) has suggested that the main motivation of TMPs in adopting these modern paraphernalia of scientific medicine is to make their practice attractive to consumers. At the structural level of adaptation, integration is manifested in the emergence of division of labour in the practice of the TMPs. Clients who present minor illnesses such as fever, abrasions, headache and sprain are attended to by assistants of TMPs due to increase in the number of clients who visit them.

\section{Cognitive integration}

Integration may also mean TMPs and SMPs learning and exchanging background knowledge 
and skills of TM and scientific medicine (Hyma and Ramesh, 1994). In other words, background knowledge and skills such as philosophies and theories behind disease causation, diagnostic and treatment methods of TM and scientific medicine are learnt and exchanged by TMPs and SMPs. According to Hyma and Ramesh (1994) cognitive integration is usually achieved by organizing TMPs and exposing them to the basic knowledge and skills of scientific medicine. The WHO states that it is also achieved by incorporating TM into the curricula of medical schools and other health training institutions.

The partnership orientation expressed in the concept of integration is reinforced by a conception that healthcare is a product of an interaction between varieties of health institutions, and it "emerges as a composite beyond the exclusive control of one system, and that it is the product of a negotiated system of interaction which yields accommodative consequences between ideologies, systems, roles and tasks" (Mauksh, 1972)

\section{Principles of Traditional Medicine}

World Health Organization (WHO) defines Traditional Medicine as a broad "set of healthcare practices, approaches, knowledge and beliefs incorporating plant, animal and mineral-based medicines, spiritual therapies, manual techniques and exercises, applied singularly or in combination to diagnose, treat and prevent illness or maintain well being"(WHO,2004:1). Ghanaians recognize what the Akans call honam yaree. It is an ordinary illness that is a result of impaired body. They also recognize bosam yaree. This illness may be experienced as a result of disruption in the relationship between the individual and the spirit world, or an attack induced by a malevolent person through supernatural powers. It is considered out of ordinary because it has been caused through invisible means. Thus, treatment of any illness episode involves either use of herbs or ritual, but most often treatment is both natural and spiritual. As a holistic approach in healthcare, TM considers the "entire physical, mental, spiritual, and social makeup of the individual in understanding the origins of illness" (Goldstein, 2000). The mainstream medicine calls these methods "unproven", "disproven", "controversial", and "questionable approaches" to solving health problems. However, a large volume of studies, has reported that this holistic approach is associated with positive health status and outcomes (Levin 1974).

The WHO (1978) considers TM as one surest means to achieve total health coverage of Ghana's population. This is because its records show that 70 per cent of Ghanaians depend on TM for their healthcare needs. Therefore at the International Conference on Primary Healthcare at Alma-Ata (USSR) that WHO sponsored in 1978, it urged all governments to integrate TM into their formal healthcare service in order to expand healthcare coverage and effectively promote the health of the people.

\section{Accessibility of TM}

In Ghana, as well as many other African countries, stakeholders acknowledge that TM plays a very important complementary role in healthcare delivery. For instance, the WHO (2002) reports, that in Ghana, Mali, Nigeria and Zambia, the first line of treatment for 60 per cent of children with high fever resulting from malaria is the use of herbal medicines at home. According to Addae-Mensah (1995), the WHO estimates conservatively that between 60 per 
cent and 90 per cent of the populations of low-income countries rely on plant medicines to meet their healthcare needs. Apart from effectiveness of plant medicine, the populations generally patronize the services of TMPs because TM is affordable, accessible and available.

The relative ratio of indigenous medical practitioners and scientific medical practitioners is quite revealing. The World Health Organization (WHO) estimates that about 70 per cent of the population in the developing world, especially Africa, depends on medicinal plants to meet their health care needs (WHO, 2002). Sarpong (2008) has noted that there is one TM practitioner to approximately 900 people in Ghana. This means TMPs are more readily accessible to more Ghanaians than their SMP counterparts, since one SMP serves approximately twelve thousand clients (MoH, 2007). SMPs are also unevenly distributed with most of them practicing in the urban areas. Amoa (2002) observes that about 25 per cent of SMPs in Ghana are located in Accra and Kumasi. Furthermore, TM is affordable, especially to the poorest patients in Ghana. In Ghana and other countries like Kenya and Mali, treating malaria with pyrimethamine/sulfadoxine is expensive (Ahorlu, 1997), whereas treating malaria with herbal medicines is very cheap and may sometimes even be paid for in kind according to the social standing of the client. These useful insights have encouraged the Government of Ghana (GoG) and the WHO to attempt a modernization of TM and eventually integrate it into the national healthcare system.

\section{National TM development Programs}

Ghana has embarked on a program to promote the modernization of TM through its Ministries, Departments and Agencies (M.D.A.s) research institutions and Universities to facilitate its integration into the national healthcare delivery system. Among the policy initiatives that have been pursued by the government are the following: 1) Technological support for research and development (R\&D), 2) Formulation and implementation of regulations and legislation 3) Promoting acceptance of TM among key stakeholders

\section{Technological support for research and development}

There are various institutions that are implementing the Government of Ghana (GoG) policy of modernizing traditional medicine through research and development. These include (a) Centre for Scientific Research into Plant Medicine (CSRPM), (b) Noguchi Memorial Institute for Medical Research (NMIMR), (c) Faculty of Pharmacy of the Kwame Nkrumah University of Science and Technology and (d) The Faculty of Science of the University of Ghana

\section{The Centre for Scientific Research into Plant Medicine (CSRPM)}

The CSRPM was established in 1974 at Mampong Akuapem in the Eastern Region of Ghana. The Centre is the brain-child of the late Dr. Oku Ampofo who graduated in 1939 after successfully pursuing a program in medicine at the University of Edinburgh. Before finally returning to the Gold Coast, he undertook short courses at the Liverpool School of Tropical Medicine. His pioneering work in herbal medicine culminated in the establishment of the CSRPM. He subsequently became its first Director. 
The Center is seen by many as a monumental testimony of the government's commitment to the modernization of traditional medicine especially its plant medicinal aspect and its eventual integration into the healthcare delivery system. The Center's objective is to produce herbal medicines of acceptable quality and effectiveness. It also conducts clinical trials at its own clinic. Physicians at the center offer treatment to clients at this clinic. The Centre's clients are treated with mostly herbal medicines developed by the center. These medicines are in liquid, powder or ointment forms. The center has a research and development unit that supervises the extraction of pure medicines in collaboration with members of Ghana Federation of Traditional Medical Practitioners (GHAFTRAM), other research institutions and commercial organizations. It also collaborates with other institutions in the collation, documentation and dissemination of the outcome of research and other technical information, and promotes.establishment of arboreta for the production of medicinal plants, where necessary.

In line with its mission, the centre conducts research into herbal medicines with the intention of isolating active constituents and providing appropriate formulations for dispensing. It undertakes this activity with the aid of a Research Committee, which supervises its research programs. The committee's membership is drawn from the Universities, Research Institutions and the Ministry of Health. They include specialists in the medical field, pharmacologists, toxicologists, biochemists and chemists.

The Center is divided into nine departments: Photochemistry, Pharmacology, Toxicology, Microbiology and Plant Development. Other departments are the Out-patient Clinic, Clinical Laboratory and Drug Production Department. These departments are staffed by a 23 member research staff made up of a qualified physician, phytochemists, and pharmacologists. The Plant Development Department manages a herbarium and an arboretum which consists of four medicinal plants gardens.

As part of its outreach program, the Centre has, in collaboration with Technoserve, an American Agri-business non-governmental organization, which supports sustainable Natural Plant Products, training programs for traditional herbalists in contemporary techniques of producing herbal medicines.

The Center affiliates with other research institutions. For instance, it conducts joint laboratory research in the production of herbal medicines with the Noguchi Memorial Institute for Medical Research (NMIMR). Its collaboration with NMIMR is aimed at establishing the toxicity, efficacy and mode of actions of herbal preparations such as indigoferra arrecta and Adenia which are used to manage diabetes mellitus and hypertension. Recently the Centre and NMIMR has engaged in an HIV and AIDS project. The purpose of the project is to ascertain the credibility of the herbalists who claim they have found a cure for HIV. Other institutions involved in this project are the Komfo Anokye Teaching Hospital (KATH) and St. Dominic's Catholic Hospital at Akwatia in the Eastern Region. Under this initiative some selected herbalists treat Persons with HIV (PLHIV). The results are encouraging. According to Essegbey (2002), the initial findings indicated that: conditions of a 
substantial number of the PLHIV have improved; the frequency of opportunistic infections has reduced considerably, some of the PLHIV have put on weight, whilst others have maintained their weight.

The future direction of the Center's activities is to improve on formulation of medicines and produce medicines in the form of capsules, tea bags and tablets. With the aid of the Commonwealth Secretariat's General and Technical Assistance Department, the Centre has purchased some equipment for the processing of herbal medicines in the form of satchel and capsules.

Other institutions that have contributed to the development of TM are, The College of Pharmacy of the Kwame Nkrumah University of Science and Technology, and The Faculty of Science at the University of Ghana These institutions have conducted several studies that have assessed the safety, efficacy and quality of TM and have produced a standard manual for assessing the safety, efficacy and quality of TM. The manual discusses safety tests such as acute toxicity, sub-chronic toxicity, chronic toxicity and teratogenicity. It also establishes quality assessment procedures such as general descriptive tests, general identity tests, purity tests, chemical assays and stability tests (shelf life) extensively and examines selected TM efficacy assessment models and procedures such as anti-hypertensive tests, anti-diabetic tests, anti-inflammatory tests and anti-ulcerative tests.

The College of Pharmacy of the Kwame Nkrumah University of Science and Technology for the past 40 years has been conducting investigations into TM in Ghana (Fleischer, 2004). The research activities are concentrated on identifying active constituents of medicinal plants and also studying the practices of traditional healers. The investigations are also aimed at validating the therapeutic effect of herbal medicines and ascertaining local sources of raw materials for the production of medicines.

During the 2001/2002 academic year, the College commenced its novel Herbal Medicine Program. This is a four-year Program leading to the award of a Bachelor of Science degree in Herbal Medicine. The first batch of students who pursued the Program passed graduated in 2005. Some of them are practicing in various private herbal clinics and herbal medicine factories across Ghana as well as the Traditional and Alternative Medicine Directorate (TAMD) as medical herbalists. Others are also serving as research assistants at CSRPM and the Herbal Medicine Department of Kwame Nkrumah University of Science and Technology.

The University of Ghana's Faculty of Science has, for sometime now, been involved in the modernization of traditional medicine in Ghana. The Faculty's Department of Botany has, in collaboration with the Centre for Scientific and Industrial Research (C.S.I.R.), executed a project named 'Herbs of Ghana', and Professor Ebenezer Laing, the then Head of Department supervised the project at its inception (Laing,1995). He and his team of researchers undertook a comprehensive taxonomic inventory of the herbaceous species of plants of Ghana. They 
came out with vernacular and scientific names of the herbs. They also identified the habitat, botanical description and the uses of these herbs. It was discovered that more than hundred species of the plants investigated have therapeutic properties.

The Departments of Biochemistry and Chemistry have also been actively involved in the verification of the efficacy and safety of numerous herbal plants. Professor Marian Ewurama Addy, formerly of the Department of Biochemistry, and her colleagues evaluated the healing effects of medicinal plants used to treat various diseases. She reports in her book "Putting Science into the Art of Healing with Herbs" (2003), that the herb, occimum canum, or the hairy basil, known by the Akan as akokJ besa, has anti-diabetic properties. Another scientist, Professor Ivan Addae-Mensah, (1992) a Phyto-Chemist, who before assuming the position of Vice-Chancellor was a Lecturer at the Department of Chemistry, reports that the plant commonly called candlewood in English and Okanto in Twi and Xetsi in Ewe is efficacious in the treatment of ailments such as sickle cell disease and hypertension (Addae-Mensah, 1992).

\section{Traditional Medicine Practice Act}

The passage of the Traditional Medicine Practice Act, 2000 (Act 575) is seen by most observers of the TM sector as an eloquent testimony of the government's commitment to modernizing traditional medicine. The Act, together with the Code of Ethics and Standard of Practice established the legal framework for the practice of TM in Ghana. The Act empowers the Council to register all traditional medical practitioners, and set standards for licensing traditional healthcare institutions. It is also intended to regulate the preparation and sale of herbal medicines and integrate traditional medical care into the national healthcare delivery system.

The Act also provides for the composition of the Council. Membership should include the healers, scientific community, officials from $\mathrm{MoH}$ and the F.D.B.

\section{The Food and Drugs Law}

The Food and Drugs Board (FDB), established under the Food and Drugs Law, 1992 (P.N.D.C.L. 305 B), is essentially a regulatory institution that certifies the production and sale of safe and efficacious herbal medicines in Ghana. The FDB carries out tests on medicines including herbal medicines manufactured and imported into this country. A number of TMPs submitted their herbal preparations to the FDB for verification. Most of these preparations have been certified by the Board as safe and efficacious. The FDB, on its own, occasionally goes to the market and picks herbal preparations for verification. Medicines that do not meet its standards are withdrawn from the market.

\section{Challenges to Integration}

However, the process of integration is beset with a number of problems. First, indigenous practice is considered as a fringe profession even by the Ministry of Health $(\mathrm{MOH})$ and the Ghana Health Service (GHS). In fact, it is only a few institutions whose traditional medical practices are officially recognized by government. A case in point is the work of the Centre 
for Scientific Research into Plant Medicine (CSRPM) at Mampong Akwapim. The center produces over 40 herbal medicines that have been certified by the Food and Drug Board for the treatment of malaria, diabetes mellitus, stomach ache and hypertension. However, none of these drugs as well as those produced by other institutions and individuals is included in the MoH's Essential Drug List. Second, the National Health Insurance Scheme (NHIS) does not cover treatment by TMPs. Third, the provisions of the Traditional Medicine Practice Act (Act 575) promulgated in the year 2000, stated among other things that a Traditional Medicine Practice Council (TMPC) should be set up to promote, control and regulate traditional medical practice in Ghana. However, the Council is not operational because the Registrar appointed to serve on it has resigned leaving a secretary to run the secretariat. Fourth, as at now, the only traditional medicine program set up in institutions of higher learning in the country is the 'special' herbal medicine program at the Kwame Nkrumah University of Science and Technology in Kumasi. The teaching of traditional medicine is not included in the curricula of the nation's medical schools and nurses' training colleges; not even at Kwame Nkrumah University of Science and Technology's Medical School.

Fifth, mainstream medical practitioners do not appear to support collaborating with indigenous medical practitioners. Medicine as a corporate body actively sought and obtained a position of dominance in health care when it was introduced into Ghana. It has used state apparatus and other mechanisms to secure monopoly right over definition, diagnosis and treatment of illness. Physicians have thus, enjoyed political and social support. No other healing occupation is considered qualified to practice the healing profession without the title medicine confers on its practitioners. The development of strong association also has given specific public and political identity to physicians, and they invoke mechanisms by which their status is acknowledged relative to other healing occupations in Ghana. Through this process, they have succeeded in eliminating or limiting the activities and of competing practices like indigenous practitioners.

\section{Attitudes of Physicians towards Integration}

The growing practice and acceptance of TM in Ghana, and the fact that the government wants to integrate it into the healthcare delivery system of the country provide a unique opportunity to assess the attitudes and perceptions of mainstream medical practitioners towards its integration into the healthcare system. More specifically, it provides an opportunity to empirically examine the following concerns physicians have about the integration of indigenous medical practices into the healthcare delivery system: 1) the extent to which mainstream practitioners are willing to accept traditional medicine as a key component of Ghana's healthcare delivery system, 2) the working relationship that exists between mainstream medical practitioners and indigenous practitioners, 3).factors that inhibit the acceptance of WHO's proposal on the working relationship between mainstream and indigenous medical systems., 4) the aspects of indigenous practices that might influence the attitudes and perceptions of physicians positively and/or negatively towards the integration of the former into Ghana's healthcare delivery system

Notwithstanding the exploratory nature of the study and the limited size of sample, the 


\section{Al Macrothink}

Journal of Sociological Research

ISSN 1948-5468

2013, Vol. 4, No.2

findings of this study offer valuable insights into the issue of integration of TM into the national healthcare delivery system and serve as a spring board for further study into this very important subject. The target population of this study was all physicians practicing medicine in the District Hospitals in Central Region of Ghana. The researcher employed the purposive sampling technique to select all the 33 physicians practicing in the 12 District Hospitals in the Central Region for the study. The rationale for selecting all allopathic doctors working in the district hospitals was two-fold. First, the $\mathrm{MoH}$ (2005) indicates in its strategic plan for Traditional and Alternative Medicine Development in Ghana, that it would sponsor a Legislative Instrument (L.I.) that would introduce practice of traditional and alternative medicine in the district hospitals. Second, just as the National Health Insurance Scheme (NHIS) was introduced in the country using district hospitals, an attempt to integrate TM into the national healthcare delivery system is most likely to start at the District Hospitals. Of the 33 allopathic doctors sampled, 21 of them work for District Hospitals managed by the Ghana Health Service (GHS), while the remaining 12 physicians practice in District Hospitals run by the local Roman Catholic Church.

After a successful pilot study, the main fieldwork started in June and ended in August, 2007. By the end of the fieldwork, the researcher had collected 25 completed questionnaires from respondents in the various hospitals with the help of two research assistants. The figure represents $86.2 \%$ of .sample size.

\section{Results and discussions}

\section{Attitudes towards integration of TM into the formal health service}

According to Eagly \& Chaiken, attitude is "a psychological tendency that is expressed by evaluating a particular entity with some degree of favor or disfavor" (1993, p.1). This study explored the evaluative orientation of SMPs towards traditional medicine. The data gathered show that both GPs and Specialists were of the view that TM should be integrated into the formal healthcare delivery system. In other words, they showed positive attitudes towards integration of TM into the national healthcare delivery system. Eight of the GPs $(66.7 \%)$ favoured integration of the two medical systems, whereas four $(33.3 \%)$ were against it. In the case of the Specialists, while $8(61.5 \%)$ supported integration of the two medical systems, only $5(38.5 \%)$ were against it. The results of this study confirm the findings of an earlier study conducted by Pearce (1982) in Nigeria where she found that a majority of the respondents $(63 \%)$ supported the integration of the two medical systems. The respondents' views with respect to their attitudes towards integration of TM into the National Health Service are presented in table 1 
Table 1: Attitudes of SMPs towards integration of traditional medicine into formal health service

\begin{tabular}{lccccc}
\hline & \multicolumn{5}{c}{ Attitudes } \\
\cline { 2 - 6 } Practitioner & S A & A & SD & D & Total \\
\hline GP & $3(25.0 \%)$ & $5(41.6 \%)$ & $1(8.4 \%)$ & $3(25.0 \%)$ & 100 \\
Specialist & $8(61.5 \%)$ & $2(15.4 \%)$ & $2(15.4 \%)$ & $1(7.7 \%)$ & 100 \\
\hline
\end{tabular}

SA- Strong Agree; A - Agree ; SD - Strongly Disagree; D - Disagree

Source:Field data (2007)

\section{Establishment of joint clinics}

Although the respondents generally supported integration of TM into the formal healthcare delivery system, they did not want to work in health institutions which have traditional medicine units or sections staffed by TMPs who are charged with the responsibility of prescribing and dispensing herbal medicines and treating illnesses. This posture of SMPs is reflected in their responses to the question 'Would you work along-side TMPs in the same clinic or hospital in Ghana?' The majority of them $16(64 \%)$ disapproved of the idea of working alongside TMPs in the same health institution. Of this, a majority who opposed the idea of working alongside TMPs, $8(50 \%)$ were GPs and another $8(50 \%)$ were Specialists. Only 4 GPs $(33.3 \%)$ of GPs and 5 Specialists (38.5) of Specialists favoured the idea that TMPs and SMPs could practice in the same healthcare facilities. One of them, a Senior Paediatrician, explained that TMPs and SMPs could complement each other. Another Senior SMP, a Gynaecologist, stated that working as a team would afford SMPs the opportunity to learn traditional medical ideas and practices. A third SMP, a Senior GP, who is in favour of setting up joint clinics for SMPs and TMPs, stated that if the setting up of joint clinics was a policy directive from the Ministry of Health $(\mathrm{MoH})$ and standards of practice and roles were clearly defined, and then he would welcome it. The respondents, who objected to the establishment of joint clinics, explained that TMPs had a different understanding of normal body functions and illness processes. One of them commented that a joint clinic is likely to generate conflict since the two medical systems were not the same. Another one, who was a senior medical officer, said that his opposition was due to the fact that the two healthcare practitioners did not similar professional orientation. In addition, another one stated that the two medical systems could not co-exist because they both had different functions and philosophies. This Scientific Medical Practitioner wondered where TMPs would fit in the national healthcare system. The observation of Pearce (1982) is similar to this finding. According to her, although SMPs generally favour integration, they disapprove of the possibility of working alongside TMPs and eventually accepting them as equal partners in the healthcare delivery system. 
Table 2: Attitudes towards establishment of joint clinics by type of Scientific Medical Practitioner

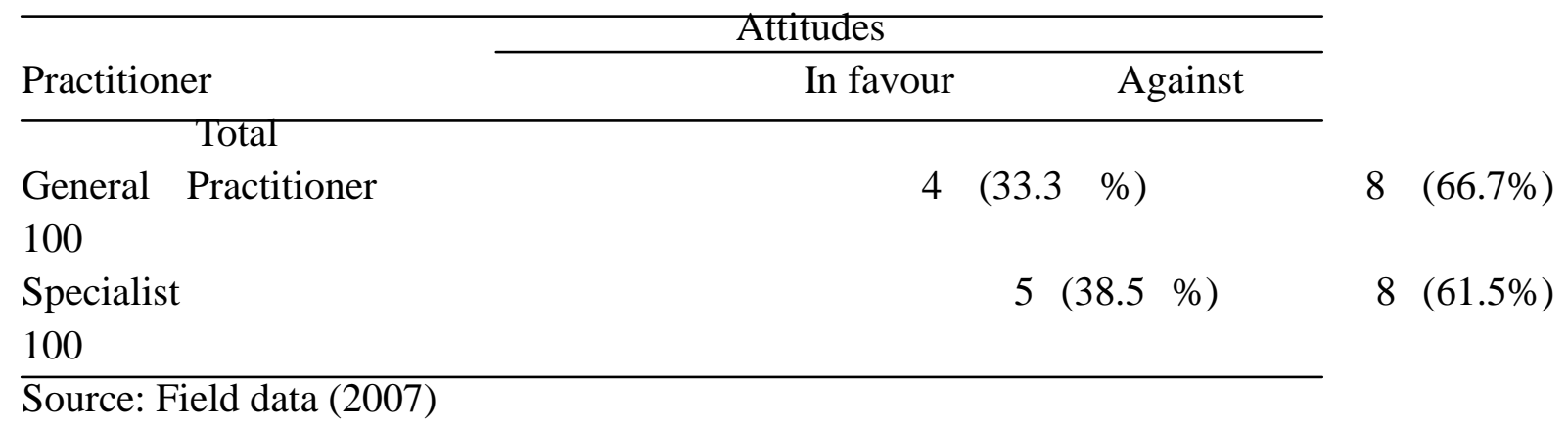

Traditional medical practices that Scientific Medical Practitioners were willing to learn A slim majority of the respondents numbering 14 (56\%) indicated that SMPs could learn a lot by collaborating with TMPs. A quarter of them (24\%) expressed interest in learning and adopting the communication strategies of TMPs. Twenty percent showed interest in learning fracture management, while only $3(12 \%)$ indicated their willingness to learn the preparation of herbal medicines. This finding is similar to that obtained by Pirota et al. (2000). They write that SMPs in Victoria, Australia, are willing to learn a whole range of traditional medical practices such as preparation of herbal medicine, meditation, acupuncture, aromatherapy, spiritual healing and hypnosis. A third of them numbering 11 (44\%) did not show interest in any of the traditional medical practices. They said there was nothing to learn from TMPs. They buttressed their position with questions like: "what can an educated person learn from an uneducated one"? These statements seem to suggest that SMPs perceive their profession to be superior to that of TMPs. Figure 1 gives a distribution of the various traditional medical practices that SMPs showed interest in learning about. 


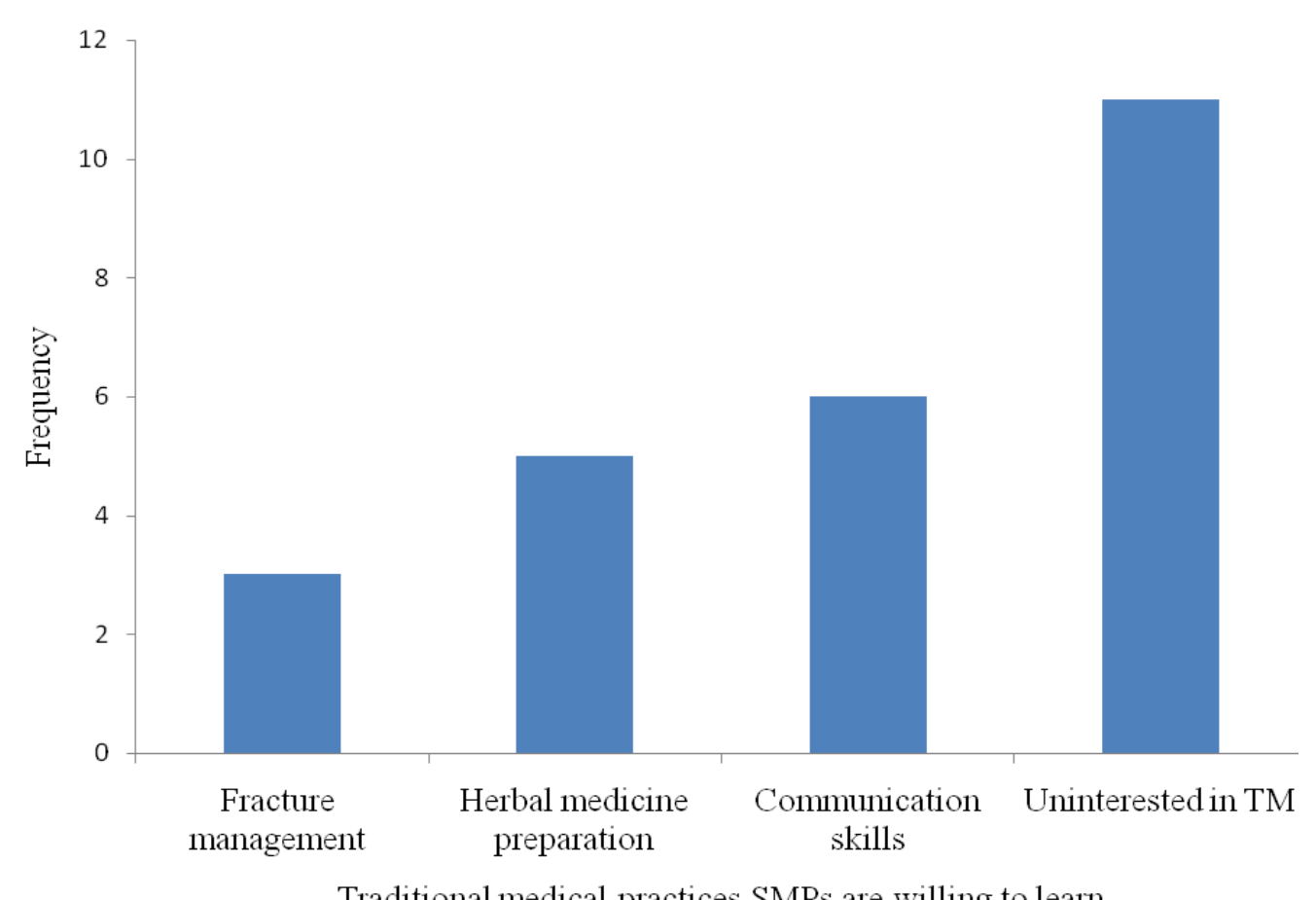

Traditional medical practices SMPs are willing to learn

Fig. 1: Traditional medical practices that Scientific Medical Practitioners are willing to learn .

Traditional Medical Practitioners who could be integrated into the health service

A substantial proportion of the respondents numbering $22(88 \%)$ indicated that TMPs such as herbalists, traditional birth attendants (TBAs) and bonesetters could easily be absorbed into the mainstream healthcare system. Out of this number 11 (44\%) specifically suggested that herbalists could be integrated into the formal healthcare delivery system; four representing $16 \%$ also suggested the inclusion of TBAs into the formal healthcare delivery system; and a little over a quarter numbering $7(28 \%)$ specifically mentioned bonesetters as the category of TMPs they thought could be easily integrated into the formal healthcare delivery system. These responses are not surprising because according to Pearce (1982), the practices and ideas behind bonesetting, herbalism and traditional midwifery are coterminous with scientific medicine. Both TM and scientific medicine stress that healing is effected mainly due to the efficacy of the drugs practitioners prescribe to their clients. Table 2 clearly depicts the categories of TMPs who, according to the respondents, could be integrated into the healthcare delivery system. 
Table 3: Traditional Medical Practitioners who could be integrated into the formal health service

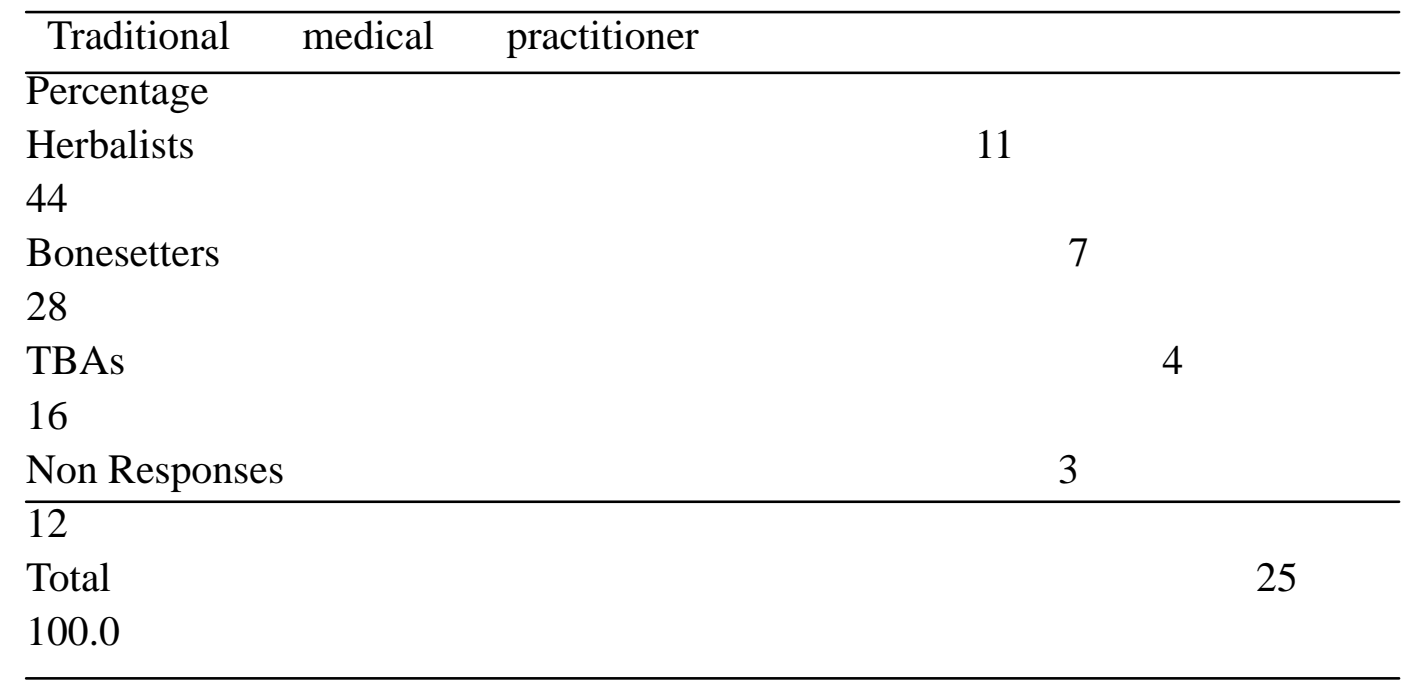

Source: Field data (2007)

\section{Conclusions}

The results of the study have led to the following main conclusions with regard to the integration of TM and its practitioners into the formal healthcare system. The first is that, although the SMPs indicated an interest in integration of the two medical systems, when confronted with possible ways of working with TMPs they showed reluctance to accept them as equal partners since they perceived their practice as inferior to theirs.

Second, it was discovered that many SMPs felt that they could learn something from some aspects of TM such as bonesetting and herbal medicine. These are the most measurable and quantifiable dimensions of traditional medical practice. The wish to learn more about these areas of TM while hesitating to absorb its practitioners brings to the foreground the problem of control and competition. In the history of the development of Scientific Medicine there have been many attempts by the practitioners to absorb or control relevant materials from other groups (e.g. granny midwives) who are perceived as threats to their dominance over medical practice. When SMPs perceive that any group was encroaching on their turf, attempts were made to control the competition.

Finally, as noted by Hyma and Ramesh (1994) institutional integration implies a harmonious co-existence of both Scientific and Traditional Medicine. The findings of the study clearly shows that integration of TM and its practitioners into the national health service at the institutional level will face some challenges.TM and its practitioners may occupy an inferior or subordinate role in the health service. Furthermore, an attempt will be made by health planners and administrators to modernize TM, thereby losing its independence and indirectly justifying the presumed superiority of Scientific Medicine.

In order to make the integration of traditional medicine into the formal healthcare system feasible it is recommended that there must be regular consultations and dialogue between and among practitioners of the two medical systems. This will help to reduce the mistrust and 
lack of understanding of the philosophy that underlie Scientific Medicine and Traditional Medicine. It may engender the needed trust and respect that the practitioners need to accord each other in order to develop and integrate TM into the national healthcare system.

Similarly, the MoH in collaboration with the Medical Schools at University of Ghana, Kwame Nkrumah University of Science and Technology, University of Cape Coast and University for Development Studies should be encouraged to introduce the teaching of traditional medicine in their curriculum. This may help the SMPs better appreciate and understand traditional medical practice.

Further, the MoH should sponsor the enactment of a Legislative Instrument to control and regulate traditional medical practice and also to allow traditional medicines to be prescribed and dispensed in public health institutions. This will also pave the way for practitioners to refer patients from one system to the other system. The $\mathrm{MoH}$ should also organise in-service training in the short and long term for traditional medical practitioners. The Bachelor of Science Herbal Medicine Programme being offered at Kwame Nkrumah University of Science and Technology should be strengthened and other universities should be encouraged to produce more medical herbalists to replace the ageing TMPs. There is the need for government to adequately make resources available to research institutions and universities for research, clinical trials and production of traditional medicines

\section{REFERENCES}

Addae-Mensah, I. (1992). Towards a rational scientific basis for herbal medicine-A Phytochemist's two-decade contribution. Accra: Ghana University Press.

Addy, M. E. (2003). Putting science into the art of healing with herbs: From

Smoked-Drum Kymograph to ELISA. Accra: Ghana Universities Press.

Addy, M. E. (2008, September 18). Cryptolepis: An African Traditional Medicine that Provides Hope for Malaria Victims. The New Legon

Observer, 2 (15), 12-16.

Ahorlu, C. K. (1997). Malaria-related beliefs and behaviour in southern Ghana: Implications for treatment, prevention and control. Tropical Medical and International Health, 2 (5), 488-499.

Amoa, S. A. (2002). Human resource chalenges and issues in health care delivery in Ghana: Suggested Options. Leadership, Management and

Administration, 1 (2), 47-68.

Annandale, E. (1998). The Sociology of Health and Medicine:

A Critical Introduction. Oxford: Blackwell. Health, Ghana.

Ayitey-Smith, E. (1988). Drugs and Fate of Humanity.Accra: Ghana Universities Press.

Ayitey-Smith, E. (1989). Prospects and scope of plant medicine in health care.Accra: Ghana Universities Press.

Bodeker, G. (2001) Lessons on integration from the developing world's experience. BMJ,322, pp.164-167. 


\section{Macrothink}

Bonsi, S. K. (2007). Doctor-Patient relationship and professional dominance in contemporary society. The Oguaa Journal of Social Science, 4 (2), 57-68.

Bonsi, S. K. (2000). Health Care. In K.Gavua (Ed.), A Handbook of Ewe land:

Vol. 2.The Northern Ewes in Ghana. Accra: Woeli Publishing Services (pp. 200-212)

Crozier, M. (1980). Actors \& Systems: The Politics of Collective Action. Chicago: University of Chicago Press.

Boje, D.M \&Whetten,D.A.(1981). Effects of organizational strategies and contextual constraints on centrality and attributions of influence in interorganizational networks. Administrative Science Quarterly, 26, 378-395. .

Dubos, R. (1960). Mirage of Health. London: George Allen and Unwin.

Eagly, A. H., \& Chaiken, S. (1993). The psychology of attitudes.

New York: Harcourt, Brace, Jovanovich.

Essegbey, G. O. (2002). Modernizing traditional medicine: The challenges. Biotech.Ghana, 2 (1), 3-6.

Evans-Anfom, E. (1986). Traditional medicine in Ghana: Practice, problems and prospects. Accra: Academy of Arts and Sciences.

Fleischer, T. C. (2004). Bachelors' degree in Herbal Medicine: Another innovation at KNUST.Technocrat, 2(1), 13-14.

Goldstein,M.S.(2000). The Growing Acceptance of Complementary and Alternative Medicine.In C. Bird,P. Conrad \& A.M.Fremont (Eds.), Handbook of Medical Sociology (pp. 284-295).New Jersey: Prentice Hall.

Hyma, B. \& Ramesh, A. (1994). Traditional Medicine: Its extent and potential for incorporation into modern national health systems. In D.R. Philips \& Y. Verhasselt (Eds.), Health and Development (pp.65-82).London: Routlege.

Laing, E. (1995) Documentation and protection of Biodiversity, with comments on protecting the intellectual rights of the Traditional Medical Practitioner. In Osofo K.D.Quarm (Chair), Traditional Medicine and Modern Healthcare: Partnerships forth future. Symposium conducted in Accra on the policies on Traditional Medicine in Ghana.

Lowengberg,J.S. (1994). Beyond Medicalisation-demedicalisation:The case of holistic health. Sociology of health \& Illness 19 (5),254-272.

Mauksch, H.O. (1972). Nursing: Churning for Change? Columbia: University of Missouri. Ministry of Health (2004). Ghana national drug policy (2 ${ }^{\text {nd }}$ edn.). Accra:

MoH Publication..

Ministry of Health (2005). A national strategic plan for traditional and alternative medicine development in Ghana (2005-2009). Accra: MoH Publication.

Ministry of Health (2007). Service availability mapping. Accra: MoH Publication. 
Nyarko, A. K. \& Asiedu-Gyekye, I. J. (2005). Safety testing. In A. K. Nyarko, I.

J. Asiedu \& Sittie, A. A. (Eds.), A manual of harmonized procedures

for assessing the safety, efficacy and quality of plant medicines in Ghana.

(pp.3-36). Accra: Ministry of Health, Ghana.

Oshikoya, K.A., Senbanjo, I.O., Njokanma, O.F. \& Soipe, A. (2008). Use of complementary and alternative medicines for children with chronic health conditions in Lagos, Nigeria. BMC ComplementaryandAlternativeMedicine, 8, 18.Retrievedfrom:http:www.biomedicalcentral.co $\mathrm{m} / 1472-6882 / 8 / 66$

Pearce, T. O. (1982). Integrating western orthodox and indigenous medicine: Professional interests and attitudes among University-Trained Physicians. Soc.Sci. Med., 16, 1611-1617.

Pirotta, M. V., Cohen, M. M., Kotsirilos, and V. \& Farish, S. J. (2000).

Complementary therapies: have they become accepted in General Practice

(Electronic version). M. J. A. 175,105-109.Retrieved July 7, 2004,

from http://www.mja.com.au/public/issues/pirotta.

Sarpong, K. (2008). Tertiary level education and training for Herbal Medicine

Practitioners. The New Legon Observer, 2 (15), 16-18.

Senah, K. (1997). Traditional and modern health care practices. In F.Agbodeka

(Ed.), A Handbook of Eweland: The Ewes of southeastern Ghana. Accra:

Woeli Publishing Services.

Sittie, A. A. (2008). Renaissance of Herbal Medicine and Safety Concerns. The New Legon Observer, 2 (12) 32-36.

Strauss,A. (2010). Continual Permutations of Action. New Jersey: Transaction Publishers.

Strauss,A. (1978). Negotiations: Varieties, Processes, Contexts, and Social Order. San Francisco: Jossy-Bass.

Twumasi, P. A. (1975). Medical Systems in Ghana: A study in medical sociology. Tema: Ghana Publishing Corporation.

Twumasi, P.A. (1988). Social foundations of the interplay between

Traditional Modern medical systems. Accra: Ghana Universities Press.

Wambabe, C. (2008). From plants to medicines: Research and development of

NIPRISAN, a drug for the treatment of sickle cell illness. The New Legon

Observer, 2 (15) 199-22.

World Health Organisation (1978) The promotion and development of

Traditional Medicine. Technical Report Series 622. Geneva:

WHO Publication.

World Health Organisation (2002). WHO Traditional Medicine Strategy:

2002- 2005. Geneva: WHO Publication. Retrieved October 14, 2005, from http://www.who.org/edm/trm.html 